\title{
Endoscopical and Histopathological Interpretation of Gastritis in Nineveh Province
}

\author{
Prof. Dr. Wahda M T Al-Nuaimy ${ }^{a}$, Dr. Huda M Faisal ${ }^{b}$ \\ ${ }^{a}$ Department of Pathology, College of Medicine, University of Mosul, Mosul, ${ }^{b}$ Pathologist, Laboratory of Pathology, Al- \\ Khanssaa Teaching Hospital, Nineveh Health Office, Mosul, Iraq. \\ Correspondence: Wahda M T Al-Nuaimy. drwahda62@yahoo.com.
}

(Ann Coll Med Mosul 2019; 41 (1):28-35).

Received: $18^{\text {th }}$ Nov. 2018; Accepted: $2^{\text {nd }}$ Jan. 2019.

\section{ABSTRACT}

Objectives: To assess the diagnostic value of endoscopical findings compared to histopathological diagnosis, to delineate the relative frequency and pattern of different types of gastritis and their association with $\mathrm{H}$. pylori and intestinal metaplasia in our locality, and to compare the results of this study with those of others.

Methods: In a cross sectional study 150 selected patients with different upper gastrointestinal symptoms have been examined at endoscopy units in Ibn-Sina teaching hospital and Al-Jamhori teaching hospital in Mosul city, from the first of June 2013 to the first of March 2014, all were assessed endoscopically and biopsies from both antral and body mucosa were taken for histopathological examination.

Results: This study has revealed gastritis histopathologically in $96.6 \%$ of cases, and the agreement between endoscopical and histophathological diagnosis was $88 \%$. The chronic superficial gastritis represented the highest relative frequency in this histopathologically diagnosed gastritis, where it was seen in $61.3 \%$ of the cases and it's relative frequency decreased with advance age, while chronic atrophic gastritis was diagnosed in $30 \%$ of the cases and it's relative frequency increased with advanced age, while gastric atrophy wasn't detected in any case. Acute gastritis was detected in only $5.3 \%$ of the cases.

Helicobacter pylori was detected in $67 \%$ of cases. A significant association was detected between chronic gastritis and Helicobacter pylori infection, and its frequency decreased with increased severity of glandular atrophy. Follicular gastritis was diagnosed in $51 \%$ of chronic atrophic gastritis and $91.3 \%$ of them were Helicobacter pylori positive cases. By the use of the special stain AB/PAS pH (2.5), intestinal metaplasia has been diagnosed in $23 \%$ of cases and it's relative frequency increased with advanced age.

Conclusion: There is a high rate of concordance (88\%) between endoscopical findings and histopathological diagnosis of gastritis. Among gastritis chronic variety was the commonest. $\mathrm{H}$. pylori had a significant association with chronic gastritis (chronic superficial gastritis and chronic atrophic gastritis). Intestinal metaplasia has been detected mainly in chronic atrophic gastritis and its frequency increased with advanced age.

Keywords: Endoscopical, histopathological, gastritis, H.pylori, intestinal metaplasia.

$$
\begin{aligned}
& \text { التفسير الناظوري والنسيج المرضي لإلتهاب المعدة في محافظة نينوى }
\end{aligned}
$$

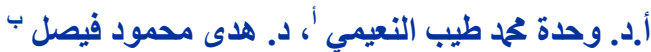

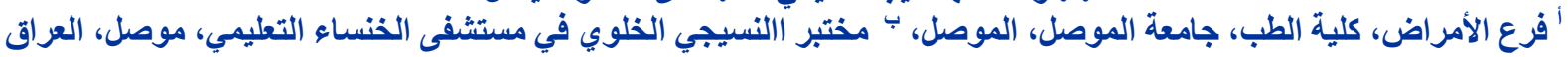

الأهداف: تهدف هذه الدر اسة الىى تحديد القيمة التشخيصية لنتائج الفحص الناظوري مقارنة بالتشخيص النسيجي المرضي وتحديد

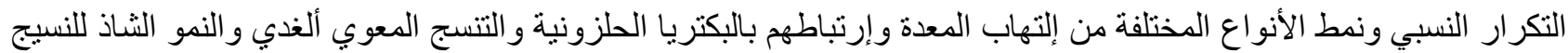

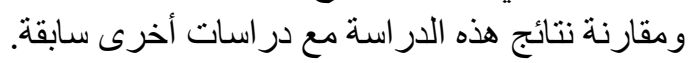




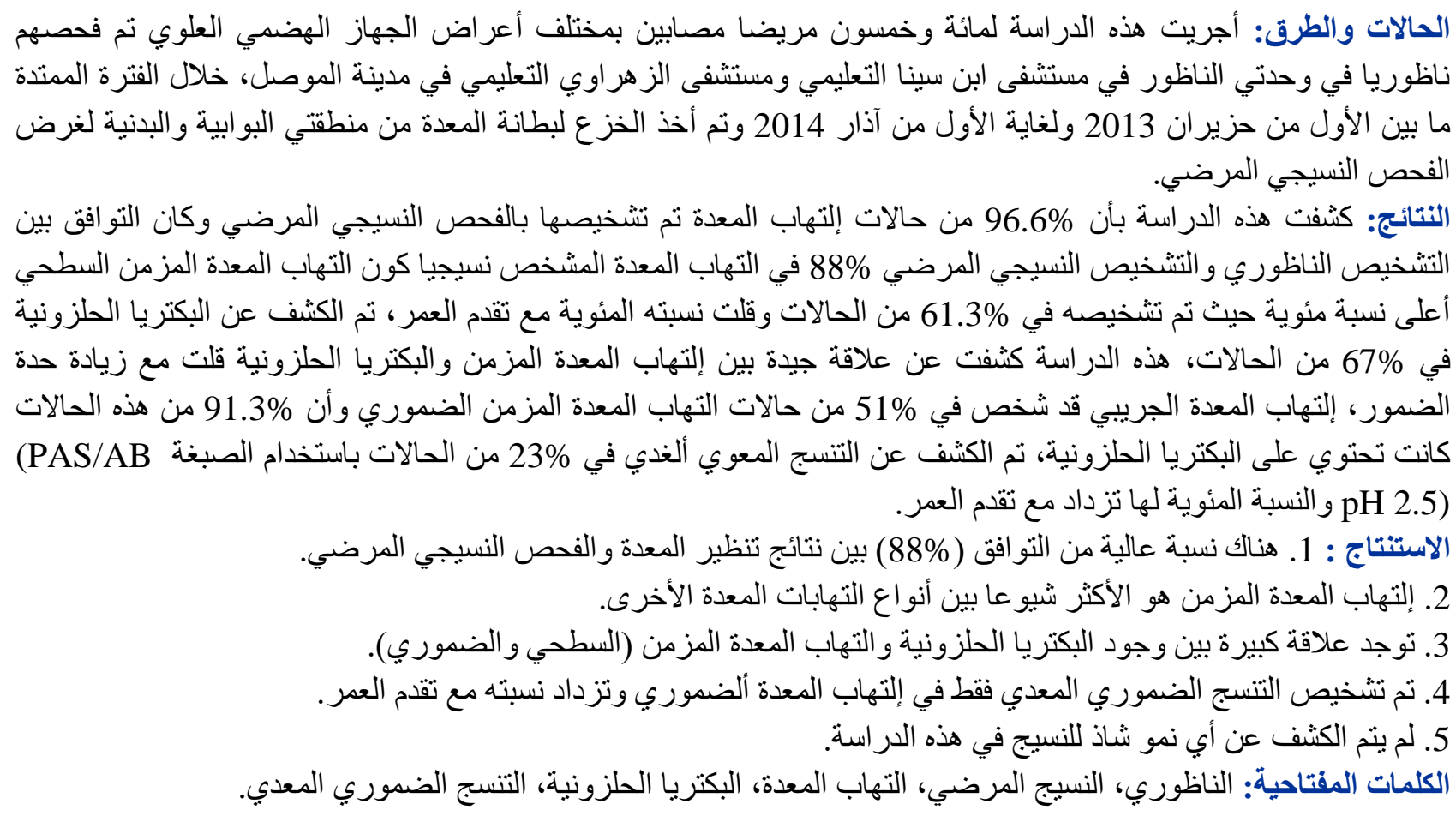

\section{INTRODUCTION}

$\mathrm{T}$ he term gastritis has a broad histopathological and topographical spectrum lead to different concepts of what gastritis is. ${ }^{1}$ Some think of it as a symptom complex, while others as a description of the endoscopic appearance of the stomach, however, it is best defined in histopathogical arm as an acute (AG) or chronic inflammation of the gastric mucosa. Chronic gastritis (CG) is distinguishable into three main categories, i.e. chronic superficial gastritis (CSG), chronic atrophic gastritis (CAG) and gastric atrophy (GA). ${ }^{2}$ There are several etiological types of gastritis, their different etiology being related to different clinical manifestation and pathological features. ${ }^{3,4} \mathrm{H}$. pylori has been established as a major etiological factor in the pathogenesis of chronic gastritis and gastric atrophy. ${ }^{5}$

An accurate diagnosis of inflammation of the stomach, can rarely be made clinically, or even on direct visualization through a gastroscope of fiberopitc tube, but it is only reliable when histopathology is available. ${ }^{6}$ There is a paucity of reports about the clinico-pathological interpretation of gastritis in Nineveh province. This study aims to assess the diagnostic value of endoscopical findings compared to histopathological diagnosis, to delineate the relative frequency and pattern of different types of gastritis and their association with H. pylori and intestinal metaplasia (IM).

\section{PATIENTS AND METHODS}

This study was reviewed and approved by the Medical Research Ethics Committee (MREC), college of Medicine, University of Mosul. With the co-operation of the medical and nursing staffs of endoscopy units in Mosul city, 150 symptomatic patients (81 males and 69 females) were selected randomly over a period of nine months started from the first of June 2013 to the first of March 2014, from endoscopy units in Ibn- Sina teaching hospital and Al- Jamhori teaching hospital. Those patients were referred to the upper GIT endoscopic units for one or more of the following symptoms; epigastric pain, dyspepsia, nausea, vomiting, and upper-gastrointestinal bleeding presenting as hematemesis and/ or malena.

Their ages ranged from 15 to 74 years, with a mean \pm SD of $(39.5 \pm 10.01)$.

The data collected from every patient included: - Name, age, sex, chief complaint and duration.

An endoscopic examination was performed after an overnight fast. All endoscopies were carried out using Olympus GIFQ- 40, under local xylocain 
spray of the throat. The findings of gastric inspection were recorded for all patients.

Gastritis was diagnosed endoscopically when there were erythematous granular erosive changes or flattening out of mucosal folds and visible submucosal vessels. Two to four biopsies were obtained in all patients from both the antrum and the body of the stomach, each measuring approximately 1-2 $\mathrm{mm}$. They were collected on filter paper and immersed in a separate labeled container, fixed by $10 \%$ formalin and routinely embedded in paraffin wax. Serial sections of $4 \mu \mathrm{m}$ thickness were cut and stained by:

1- Hematoxylin and Eosin (H\&E) for histopathological assessment.

2- Modified Giemsa stain for detection of $\mathrm{H}$. pylori ,which was stained blue to purple.

3- Special stain which is a combined of Alcian Blue /Periodic Acid Shiff (AB/PAS) pH (2.5), was used to identify neutral and acidic mucin (sulfomucins and sialomucins) for the detection of IM , which was stained blue ( $A B$ positive and PAS negative) while the normal gastric mucosal glands were stained magenta (PAS Positive and AB negative).

The histopatological findings in the gastric biopsies were classified into: Normal, Acute Gastritis or Chronic Gastritis.

Grading of chronic gastritis was assessed by the criteria of Whitehead et al of chronic gastritis (CG) as chronic superficial gastritis (CSG), chronic atrophic gastritis (CAG) and gastric atrophy (GA). ${ }^{4}$ The clinical and pathological data of the studied patients were reviewed and entered into a computerized database. The statistical analysis included the mean $(\bar{x}), \pm S D$, range, and Chisquare test. ${ }^{7} \mathrm{P}$ value equal or less than 0.05 was considered significant.

\section{RESULTS}

Among the 150 symptomatic patients, there were $81(54 \%)$ males with a mean age \pm SD of $(39 \pm 5.5)$ years, and 69 (46\%) females with a mean age \pm SD of $(40 \pm 5.08)$ years. The peak age was at the $6^{\text {th }}$ decade.

The endoscopic examination revealed normal gastric mucosa in $13(9 \%)$ patients out of the total 150 patients. The histopathological findings of these 13 patient revealed that 4 (30\%) patients showed antral gastritis, 1 (8\%) patients showed body gastritis, and the remaining 8 (62\%) exhibited both antral and body gastritis.

The remaining 137 (91\%) patients showed abnormal gastric mucosa (gastritis) on endoscopical examination. On histopathological examination, 5 (4\%) patients showed normal gastric mucosa, 10 (7\%) patients showed antral gastritis, 4 (3\%) patients revealed body gastritis, while the remaining 118 (86\%) patients showed both antral and body gastritis.

Among the 145 (96.6\%) patients with gastritis histopathologically, acute gastritis as shown in (Fig. 1) was diagnosed in $8(5.3 \%)$ of them and there was no significant association ( $P$ value 0.19 ) in different age groups. CSG as shown in (Fig. 2 and 3 ) was detected in $92(61.3 \%)$ of the patients, which represented the highest relative frequency and it declined with advanced age. CAG as shown in (Fig. 4) was found in 45 (30\%) of the patients and the relative frequency increased with advanced age as shown in (Fig. 5). While GA wasn't detected in any case.

By the use of modified Giemsa stain $\mathrm{H}$. pylori as shown in (Fig. 6) was detected in 101 (67\%) of the patients, and the relative frequency of this distribution increased with advanced age.

$H$. pylori was detected in one $(20 \%)$ patient with normal gastric biopsy, in 3 (38\%) patients with acute gastritis, and the highest relative frequency was found in patients with CSG and CAG, where it was found in 73 (79\%) and 24 (53\%) patients respectively.

The frequency of $\mathrm{H}$. pylori decreased with the increased severity of gastric atrophy as shown in (Table 1) with $P$ value (0.04)

$\mathrm{H}$. pylori was detected in $97(71 \%)$ of patients with CG, while acute on chronic gastritis as shown in (Fig. 7) was diagnosed in $58(60 \%)$ of $\mathrm{H}$. pylori positive patients.

By the use of the special stain AB/PAS pH (2.5), $\mathrm{IM}$ as shown in (Fig. 8) was encountered in 34 (23\%) of all patients. The relative frequency of IM was increased with increasing age and the peak frequency was found among patients in the age group (71-80) with $P$ value (0.03).

The current study showed that the highest relative frequency of IM 32 (94\%) was found in CAG, while only 2 (6\%) of cases with IM was found in CSG. IM was not found in $A G$ and normal gastric biopsies. 
Follicular Gastritis was diagnosed in 23 (51\%) patients with CAG. Twenty- one (91.3\%) patients were $\mathrm{H}$. pylori positive, while only $2(8.7 \%)$ patients were $\mathrm{H}$. pylori negative.

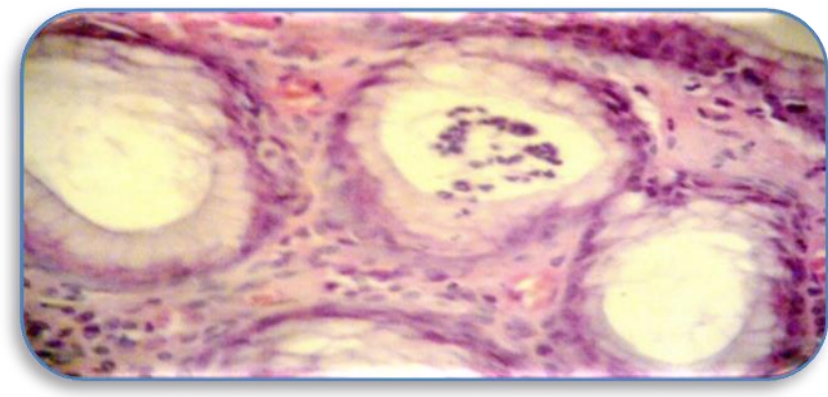

Figure 1: Acute gastritis with crypt abscess (H\&E $\times 400)$.

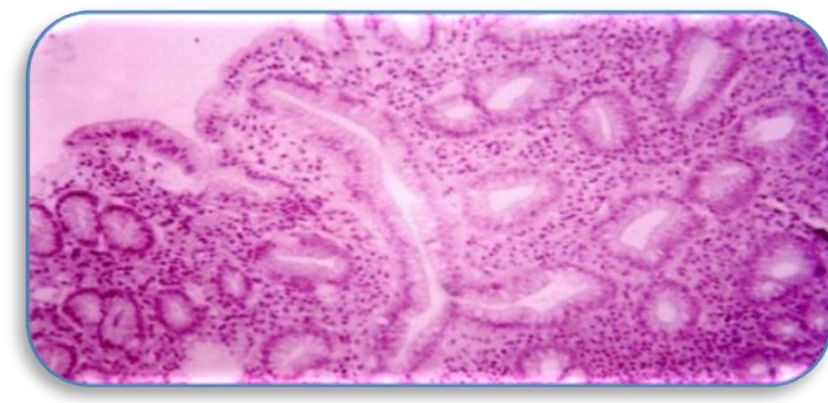

Figure 2: Chronic superficial gastritis (antrum) (H\&E $\times 100)$.

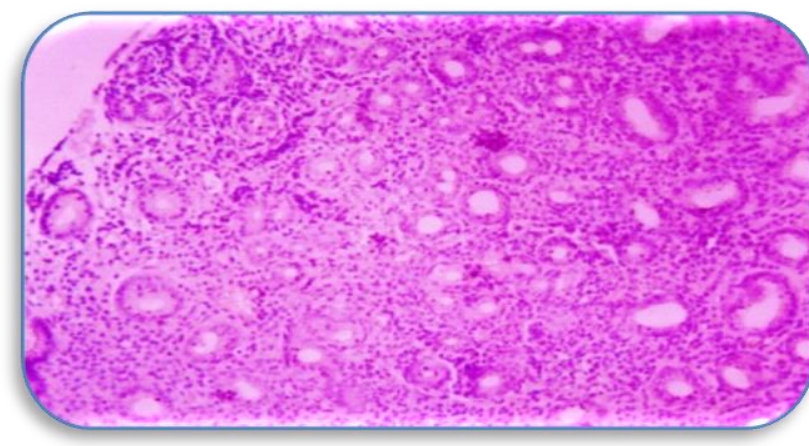

Figure 3: Chronic superficial gastritis (body) $(H \& E \times 100)$.

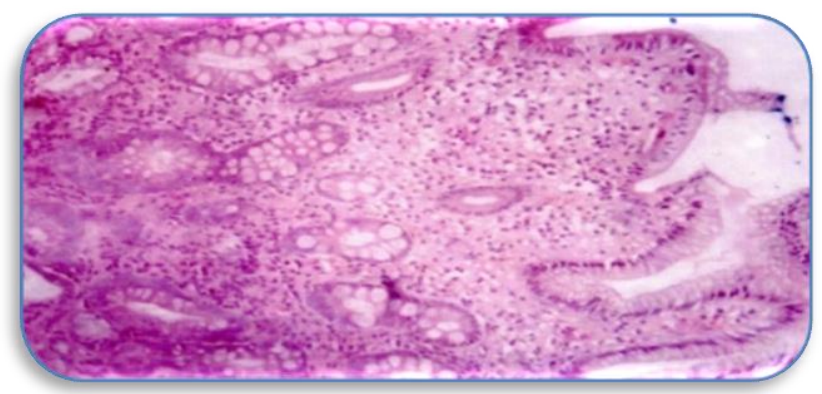

Figure 4: Chronic atrophic gastritis with intestinal metaplasia $(H \& E \times 100)$.

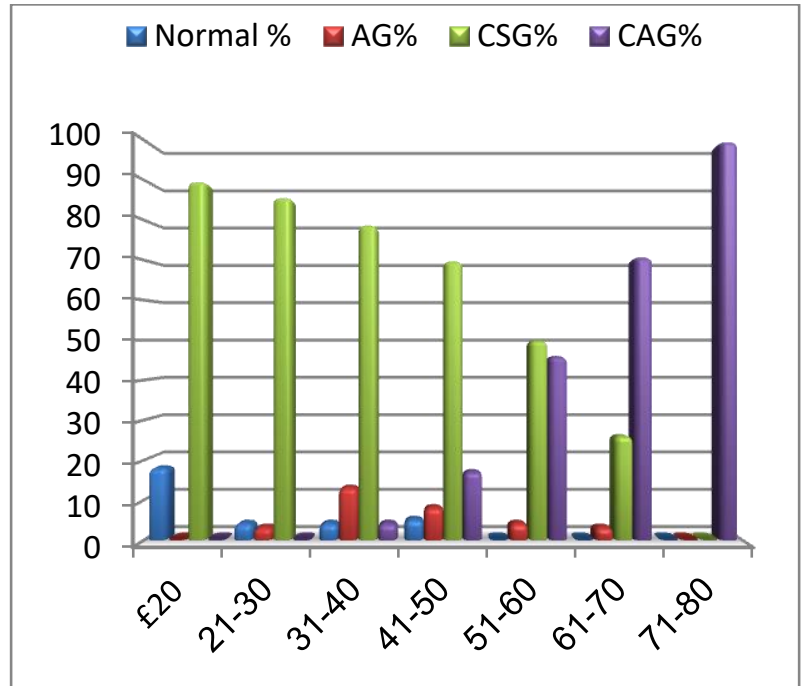

Figure 5: Frequency of different types of gastritis in relation to age groups.

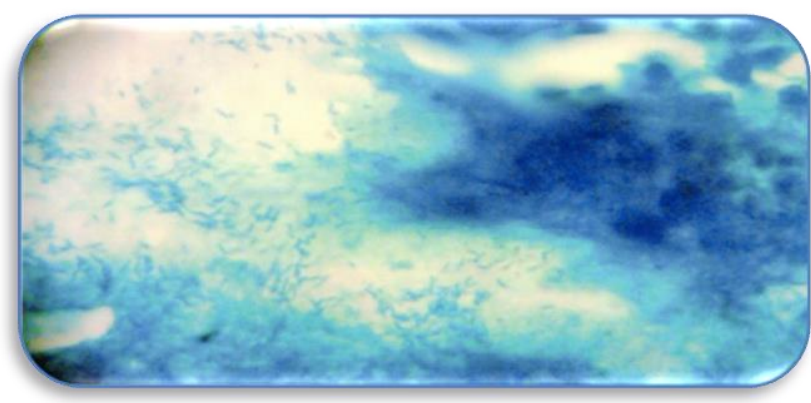

Figure 6: Helicobacter pylori (Giemsa stain ×1000)

Table 1: The frequency of $\mathrm{H}$. pylori according to severity of gastric atrophy in chronic atrophic gastritis.

\begin{tabular}{lccccc}
\hline $\begin{array}{l}\text { Grading of Gastric } \\
\text { Atrophy }\end{array}$ & No. & & \multicolumn{2}{c}{ H. pylori + ve } \\
\cline { 4 - 6 } Mild & & & No. & $\%$ \\
Moderate & 29 & 64 & 17 & 38 \\
Severe & 12 & 27 & 6 & 13 \\
Total & 4 & 9 & 1 & 2 \\
\hline
\end{tabular}

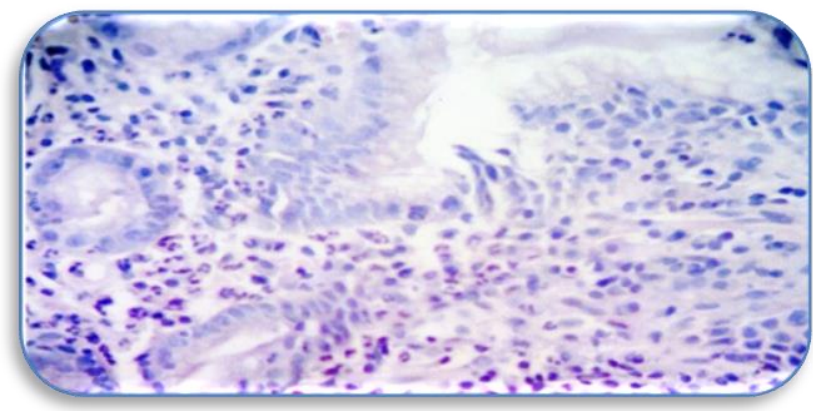

Figure 7: Acute on chronic gastritis $(H \& E \times 400)$. 


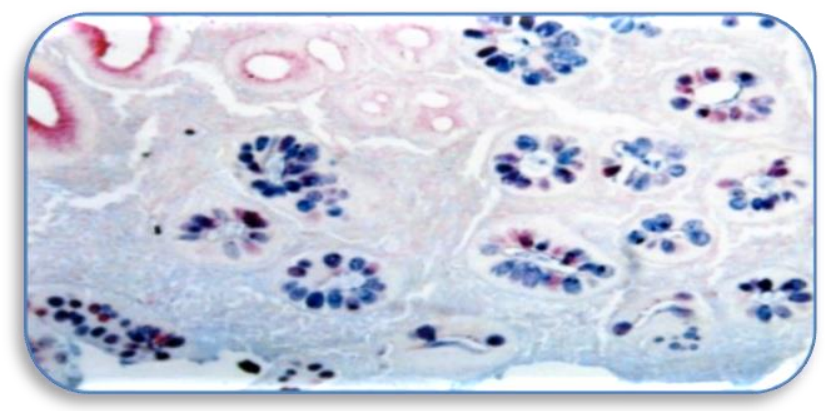

Figure 8: Intestinal metaplasia, showing goblet cells containing acidic mucin is stained blue $(A B+v e)$ and normal gastric mucosa containing neutral mucin is stained magenta (PAS +ve.). (AB/PAS stain $\mathrm{pH} 2.5$ $\times 400)$.

\section{DISCUSSION}

Gastritis is common endoscopic finding, however, reports on the value of endoscopy alone for the diagnosis of gastritis is still controversial. ${ }^{5,6}$ It is a very common lesion even in normal population but is real prevalence is difficult to be estimated precisely because so many are asymptomatic and may not come under medical attention. ${ }^{6}$ On the other hand, it is definitely diagnosed only through histopathological examination of gastric biopsy which is an invasive and not an easy technique. ${ }^{8,9}$ In this study gastritis was diagnosed histopathologically in $96.6 \%$ of the sampled patients. Acute gastritis was diagnosed in $5.3 \%$, while CG was diagnosed in $91.3 \%$ of the cases. These results are comparable with those in study done by Asa'ad SK ${ }^{9}$ where gastritis was diagnosed in $96 \%$ of cases; $4 \%$ were $A G$ and $92 \%$ were CG. But not with Al-Hadithi RH and Al-Hadithi $\mathrm{TM}^{6}{ }^{6}$ who diagnosed CG histopathologically in $70 \%$ of the cases and Susana MK et al ${ }^{10}$ where acute gastritis diagnosed in $73.38 \%$ while, $26.62 \%$ diagnosed as CG.

In the present study, $9 \%$ of histopathologically diagnosed gastritis had normal endoscopical finding. The concordance between the endoscopical and the histopthological diagnoses was $88 \%$ which is comparable to the results obtained by AL Hamadani AA et al ${ }^{11}$, Hamodi $S$ and Rasheed NW, ${ }^{12}$ and by Awaad K. A. et al ${ }^{13}$, where their results was (86\%), (91.7\%) and $(90.2 \%)$ respectively. However, this figure is higher than the $76.4 \%$ reported by Hassan $\mathrm{TMM}^{5}$ and $40 \%$ reported by Poudel A. et al ${ }^{3}$.The reasons for this lack of correlation between the endoscopical and the histopathological diagnosis of gastritis, which were observed in different comparative studies of gastritis are unclear. The variations in the endoscopic interpretation of gastric biopsy may be partly responsible. In addition, the patchy distribution of the inflammatory conditions of the gastric mucosa may add further difficulties in their recognition. This would necessitate proper site biopsies, and multiple sections for their histopathological interpretation ${ }^{14}$.

According to the anatomical distribution of the histopathological findings, antral gastritis was diagnosed in $9.3 \%$ of the cases body gastritis in $3.3 \%$, and both antral and body gastritis in $84 \%$ of the cases. These results, are relatively similar to the results obtained from the study of Asa'ad SK, ${ }^{9}$ where antral gastritis had been found in $10 \%$, body gastritis in 4\%, and both antral and body gastritis in $82 \%$ of the cases. On the other hand, these results are quite different from those of Awwad K.A. et al ${ }^{13}$,where gastritis was mainly present in the antral mucosa in $63 \%$, followed by antral predominant pan gastritis in $13 \%$ and corpus predominant gastritis in $7 \%$.

Different types of gastritis were diagnosed histopthologically. CSG is the commonest type, where it was diagnosed in $61.3 \%$ of patient, CAG was encountered in $30 \%$ of patients. While AG was found in $5.3 \%$ of the cases. These findings are relatively similar to those of other studies done in Iraq including Hamodi $S$ and Rasheed NW ${ }^{12}$ and Poudel A. et al where CSG in $58 \%$ and $A G$ in9.3\%.

In this study, it has been found that the relative frequency of CSG declines with advanced age. Similar results were also obtained by Asa'ad SK ${ }^{9}$. This may be due to the fact that if CSG did not regress to normal by treatment, it may progress to CAG over a period of decades ${ }^{15}$

In this study there is no significant association with $p$ value 0.07 between sex distribution and gastritis, which is similar to what was found by Asa'ad SK ${ }^{9}$.

$\mathrm{H}$. pylori is a common bacterial infection of the gastric mucosa all over the world. ${ }^{16-32}$ It is known to cause gastritis and plays a significant role in the development of active chronic gastritis. ${ }^{19}$ Chronic infection with $\mathrm{H}$. pylori may lead to glandular atrophy and IM. ${ }^{16,18,24,25,33-41}$

It had been shown that the frequency of $\mathrm{H}$. Pylori infection increased with advanced age. ${ }^{19,20}$ This in 
agreement with the result of this study, where the number of $\mathrm{H}$. Pylori positive case increased with advanced age also. This finding was also revealed by Asa'ad SK ${ }^{9}$ and Latif $A$ and Azadeh $A,{ }^{21}$ while it different from Khan AR. ${ }^{22}$

In this study there is no significant association between $\mathrm{H}$. pylori infection and sex distribution with $p$ value 0.063 , which is similar to the results of Asa'ad SK ${ }^{9}$ and Khan AR. ${ }^{22}$ And differ from that reported by lbrahim $A,{ }^{23}$ who found that $H$. Pylori is more predominant in male.

The relative frequency of both $\mathrm{CAG}$ and $\mathrm{H}$. pylori infection increased with advanced age, as in this study which is comparable with that result obtained from Asa'ad SK. ${ }^{9}$ This supports the fact that $\mathrm{H}$. pylori acts as a critical factor leading to progression of CSG to CAG with advanced age. ${ }^{24}$ This might explain the high frequency of CAG in this study which was $30 \%$ compared to only $9.3 \%$ and $14.9 \%$ reported by Poudel $\mathrm{A}$ et $\mathrm{al}^{\beta}$ and Susana $\mathrm{MK}^{10}$ respectively.

The relative frequency of $\mathrm{H}$. pylori infection in this study was $67 \%$ which is within the range of the results of most studies which we compared with as shown in (Table i).

In all these studies different diagnostic methods were used for the diagnosis of $\mathrm{H}$. pylori. These included (histopathological diagnosis with different staining methods, urease test, serology, and culture), and they were either used in combination or separately. Each test has a different sensitivity and specificity.

In addition ,Yokoi $\mathrm{T}$ et $\mathrm{a}^{\mathrm{F}^{7}}$ had found that the use of filter paper will decrease the sensitivity (or increase the rate of false negative result for diagnosis of $\mathrm{H}$. pylori) because the use of filter papers for gastric biopsy collection may result in the entrapment of $\mathrm{H}$. pylori in their substance. ${ }^{27}$

In the present study, a significant association was revealed between $C G$ and $H$. pylori infection where $\mathrm{H}$. pylori has statistically a significant association with CSG and CAG ( $p$ value 0.001 and 0.01 ) respectively. The highest relative frequency of $\mathrm{H}$. pylori infection was found in patients with CSG (79\%) and CAG (53\%). The same results were reported by Abdul Jabbar $\mathrm{B}^{26}$.This indicates that $\mathrm{H}$. pylori is the major cause of inflammation in the gastric mucosa.
Table i. The reported frequency of $\mathrm{H}$. Pylori infection by different diagnostic methods.

\begin{tabular}{|c|c|c|c|c|}
\hline AUTHOR & YEAR & $\begin{array}{l}\text { NO. OF } \\
\text { PATIENI } \\
\text { S }\end{array}$ & $\begin{array}{c}\text { FREQUNCY } \\
\text { OF H. } \\
\text { PYLORI }\end{array}$ & $\begin{array}{l}\text { DIAGNOSTIC } \\
\text { METHODS }\end{array}$ \\
\hline $\begin{array}{l}\text { Mohamed } \\
\mathrm{AE} \text { et } \\
a l^{(41)}\end{array}$ & 1994 & 382 & $61.64 \%$ & $\begin{array}{l}\text { H. p antrum } \\
\text { Giemsa stain }\end{array}$ \\
\hline $\begin{array}{l}\text { Ibrahim } \\
\mathrm{BH} \text { et } \\
\mathrm{al}^{(38)}\end{array}$ & 1995 & 286 & $81.7 \%$ & $\begin{array}{c}\text { H. p antrum } \\
\text { Hand } E\end{array}$ \\
\hline $\begin{array}{l}\text { Abdul } \\
\text { Jabbar B } \\
\text { et }\left.a\right|^{(26)}\end{array}$ & 1997 & 81 & $75.3 \%$ & $\begin{array}{l}\text { H. p (antrum ) } \\
\text { different stain }\end{array}$ \\
\hline $\begin{array}{l}\text { Asa'ad } \\
\text { SK et al } \\
\text { (9) }\end{array}$ & 2000 & 50 & $84 \%$ & $\begin{array}{l}\text { H. p antrum } \\
\text { and body } \\
\text { Giemsa stain }\end{array}$ \\
\hline $\begin{array}{l}\text { Mansoor } \\
I^{(40)}\end{array}$ & 2001 & 540 & $66.6 \%$ & $\begin{array}{l}\text { H.p (antrum) } \\
\text { different stain }\end{array}$ \\
\hline $\begin{array}{l}\text { Latif } A \\
\text { and } \\
\text { Azadeh } \\
A^{(21)}\end{array}$ & 2002 & 574 & $77 \%$ & $\begin{array}{l}\text { H. p (antrum) } \\
\text { UT and } \\
\text { Giemsa stain }\end{array}$ \\
\hline $\begin{array}{l}\text { Susana } \\
\mathrm{MK}^{(10)}\end{array}$ & 2009 & 154 & $23.37 \%$ & $\begin{array}{c}\text { H. p } \\
\text { (antrumand } \\
\text { corpus) } \\
\text { Giemsa and } \\
\text { silver stains }\end{array}$ \\
\hline $\begin{array}{l}\text { Poudel A. } \\
\text { et al }\end{array}$ & 2013 & 43 & $41.9 \%$ & $\begin{array}{l}\text { H. p (antrum } \\
\text { and body) } \\
\text { Giemsa stain }\end{array}$ \\
\hline $\begin{array}{l}\text { Awwad K } \\
\text { A et al }{ }^{(13)}\end{array}$ & 2014 & 100 & $92 \%$ & $\begin{array}{l}\text { H. p (antrum } \\
\text { and body) } \\
\text { Giemsa stain }\end{array}$ \\
\hline $\begin{array}{l}\text { Myint T } \\
\text { et al }{ }^{(25)}\end{array}$ & 2015 & 252 & $48 \%$ & $\begin{array}{l}\text { H. P (antrum } \\
\text { and body) H } \\
\text { and } \mathrm{E}, \\
\text { serology, } \\
\text { culture and } \\
\text { immunohistoc } \\
\text { hemistry. }\end{array}$ \\
\hline $\begin{array}{l}\text { Hassan } \\
\text { TMM }^{(5)}\end{array}$ & 2016 & 157 & $93.7 \%$ & $\begin{array}{l}\text { H. p (antrum } \\
\text { and body) } \\
\text { Giemsa stain }\end{array}$ \\
\hline $\begin{array}{l}\text { Elsawaf } \\
\text { ZM et } \\
\left.a\right|^{(28)}\end{array}$ & 2017 & 1236 & $32.5 \%$ & $\begin{array}{l}\text { H. p(antrum } \\
\text { and body) } \\
\text { Giemsa stain }\end{array}$ \\
\hline $\begin{array}{l}\text { Present } \\
\text { study }\end{array}$ & 2018 & 150 & $67 \%$ & $\begin{array}{l}\text { H. p (antrum } \\
\text { and body) } \\
\text { Giemsa stain }\end{array}$ \\
\hline
\end{tabular}

$\mathrm{H}$. pylori is diagnosed in $38 \%$ of patients with $A G$, a figure similar to $37.7 \%$ that obtained from the study of Asa'ad $\mathrm{SK}^{9}$ and higher than $0.9 \%$ which observed by ELsawaf ZM et $a f^{28}$. This may be behind the fact that the initial infection could be followed by AG.

Infection with $\mathrm{H}$. pylori is thought to lead to the development of CAG and the mechanism by which the inflammation leads to atrophy is that florid inflammatory response may lead to continuing destruction of the epithelial glandular structure and 
damage to the generative zone which may result in selective loss of regenerative capabilities for the glandular compartments. ${ }^{15}$

Some investigators reported that the frequency and density of $\mathrm{H}$. pylori in CAG decrease significantly with the increases in the grade of glandular atrophy. ${ }^{1,29}$ This finding is in accordance with the result of this study, where the frequency of $H$. pylori infection decreased with the increase of the severity of the glandular atrophy as $\mathrm{H}$. pylori was found to be present in $38 \%$ of mild CAG, $13 \%$ of moderate CAG, and in only $2 \%$ of severe CAG with $p$ value $(0.04)$.

The neutrophil infiltration (acute gastritis) is seen predominantly in areas where the $H$. pylori organisms are most abundant and most readily identified. ${ }^{37}$

In this study acute on chronic gastritis was seen in $(60 \%)$ of $\mathrm{H}$. pylori positive patients which is relatively similar to the figure of $(59.8 \%)$ that has been reported by lbrahim et ${ }^{3}{ }^{38}$ but lower than $(82.5 \%)$, and $(73.5 \%)$ reported by ELsawaf ZM et $a l^{28}$ and Susana MK et $a l^{10}$ respectively, and higher than $33 \%$ reported by Garg B et al. ${ }^{30}$ These differences in the results may be due to the fact that in $H$. pylori associated gastritis, polymorphnuclear cells are predominantly within the lamina propria and at the base of the gastric pits rather than within the surface epithelial layer. This reflects the small number of polymorphonuclear cells on the surface epithelium, and only polymorphs lying strictly within the surface epithelial layer were counted, while those lying deeper were not counted. ${ }^{31}$

Follicular Gastritis is present in almost $100 \%$ of $\mathrm{H}$. pylori positive cases if sufficient number of biopsies were taken. ${ }^{32}$ In this study follicular gastritis was diagnosed in (51\%) of CAG; $(91.3 \%)$ were $\mathrm{H}$. pylori positive. The reason for the $\mathrm{H}$. pylori negative cases, is suggested to as such; either the organism has been missed (overlooked or not present), or that the infection has been cleared. ${ }^{1}$

Intestinal Metaplasia results from faulty regeneration of a mucosa repeatedly damaged by gastritis. ${ }^{33}$ It represents a protective change to chronic infection by $\mathrm{H}$. pylori because epithelial cells look in their genetic background for the possibility to exclude the infection. ${ }^{34}$

In the present study IM has been diagnosed by the use of special stain AB/PAS pH (2.5) in (23\%) of all patients. This is near to the frequency of (21.3\%) reported by Olaejirinde et al, ${ }^{35}$ and higher than $16.23 \%$ reported by Suzana MK, et al ${ }^{10}$ and $15 \%$ reported by Hassawi BA et $a f^{36}$.

A significant association was found in this study between the relative frequency of $\mathrm{IM}$ and the increase with advanced age. This finding is consistent with a study done by Craanen ME et al, ${ }^{39}$ with the fact that $I M$ is an age related phenomenon and its prevalence is higher in older subjects ${ }^{4}$.

\section{CONCLUSION}

There is a high rate of concordance (88\%) between endoscopical and histopathological findings. Among gastritis chronic variety was the commonest. $\mathrm{H}$. pylori had a significant association with chronic gastritis (CSG and CAG). Intestinal metaplasia has been detected mainly in CAG and its frequency increased with advanced age.

\section{REFERENCES}

1. Dixon MF, Genta RM, Yardley JH, et al. Classification and grading of gastritis. The update Sydney system. International workshop on the histopathology of gastritis, Houston 1994 Am J Surg Pathol 1996; 20(10): 1161-81.

2. Massimo R. Gastritis the histological report. J Dig liver dis 2011;43:S373-84

3. Poudel A, Regmi S, Poudel S, et al. Correlation between endoscopic and histopathological findings in gastric lesions. JUCMS 2013;1(3):37-41.

4. Whitehead R, Truelove Sc, and Gear MWL. The histological diagnosis of chronic gastritis in fibreoptic gastroscopy biopsy gastroscopy biopsy specimens. J Clin Pathol 1972; 25: 1-11.

5. Hassan TMM. Helicobacter Pylori chronic gastritis updated Sydney grading in relation to endoscopic findings and $\mathrm{H}$. Pylori lgG antibody: diagnostic methods. JMAU 2016;4:167-74.

6. Al- Hadithi RH and Al- Hadithi TM. Endoscopic and hisological study in chronic gastritis. Iraqi J Med Sic 2000;1(1):3-8.

7. Armitage $P$. Statistical methods in medical research $6^{\text {th }}$ ed. 1988. Oxford, Blachwell. p.50-54.

8. Razzak A. Histopathological study of gastric biopsies in patients with gastric dyspepsia in Duhok city. Z J M S 1998-2000;4(1-2):48-51

9. Asa'ad Sk. Clinical, endoscopical, and histopathological prospective study of gastritis. A thesis submitted to the Iraqi commission for medical specialization in pathology 2000. p.73-79.

10. Susana MK, and Telaku S. Helicobacter Pylori Gastritis Updated Sydney classification applied in our material. Contributions. J Sec Biol Sci 2009;1: 45-60.

11. AL-Hamadani AA, Fayady $A$, and Abdul Majeed BA. Helicobacter Pylori gastritis correlation between endoscopic and histological finding. IJGE 2001;1:43-8. 
12. Hamodi S, and Rasheed NW. Upper GIT lesions endoscopic and histopathological study. Iraqi postgraduate Med J 2001;1(3):212-5.

13. Awwad K.A. ALenezy and Taha Hassan MM. Helicobacter Pylori associated chronic gastritis: endoscopic and pathological findings, comparative study. Int J Genetic Mol Biol 2014;6(2):23-8

14. Elta HG, Appelman HD, Behhler EM, et al. A study of the correlation between endoscopic and histopathological diagnosis in gastroduodenitis. Am J Gastroenterol 1987;82(8):749-53.

15. Satoh K, Kimura K, Taniguchi y et al. Distribution of inflammation and atrophy in the stomach of $\mathrm{H}$. pyloriPositive and negative Patients with chronic gastritis. Am J Gastroenterol 1996;91(5):963-8.

16. Ju. Yuplee and Nayoung Kim. Diagnosis of Helicobacter Pylori by invasive test. J Ann Transl Med. 2015;3(1):10-8.

17. Ranbeer Singh, Taneji Vijay Laxmi, Verma K S, et al. Chronic Gastritis: Helicobacter Pylori infection: A ClinicoEndoscopic and Histopathological evaluation. GJRA 2017;6(2):32-5.

18. Kokkola A, Rautelin $\mathrm{H}$, Puolakkainen $\mathrm{P}$, et al. Diagnosis of Helicobacter Pylori infection in patients with atrophic gastritis: comparison of histology, $13 \mathrm{C}$ urea breast test, and serology. Scand J Gastroenterol 2000;35:138-41.

19. Blanchard TG, Czinns J.J. H.Pylori acquisition and transmission where does it all begin. J Gastroenterol 2001;121:438-85.

20. Harris A W, Misiewicz JJ. Helicobacter pylori. $5^{\text {th }}$ ed. 1996. Blackwell Healthcare Communications. p. 5,6,2633.

21. Latif $A$, Azadeh A. H. pylori gastritis in Qatar. Qatar Med J 2002;11 (2);12-5.

22. Khan AR. An age and gender specific analysis of $H$. pylori infection. J Ann Saudi Med 1998;18(1):6-8.

23. Ibrahim A. Sex difference in the prevalence of Helicobacter Pylori infection in pediatric and adult populations: Systematic review and data - analysis of 244 studies. J Dig liver dis 2017;49(7):742-9.

24. Kawaguchi $\mathrm{H}$, Harama $\mathrm{K}$, Komoto $\mathrm{K}$, et al. $\mathrm{H}$. pylori infection is the major risk factor for atrophic gastritis. Am J Gastroenterol 1996; 91(5):656-62.

25. Myint T, Shiotas, VilaichoneRk, et al. Prevalence of Helicobacter Pylori infection and atrophic gastritis in patients with dyspeptic symptoms. World J Gastroenterol 2015;21:629-36.

26. Abdul Jabbar B. The demonstration of $\mathrm{H}$. pylori in the gastroduodenal endoscopic biopsies by using different stains. A thesis submitted to the Iraqi Commission for medical specialization in pathology, 1997.
27. Yokoi T, Yoshikane H, Hamajima E, et al. Evaluation of handling methods in the histological diagnosis of $\mathrm{H}$. pylori: The effect of filter paper Am J Gastroenterol 1996;91(11):2344-6.

28. Elswaf ZM, ALbasri, A.S. Hussainy, et al. Histopathological pattern of benign endoscopic gastric biopsies in Saudi Arabia: A review of 1236 cases. JPMA 2017;67:252-5.

29. WGO article. World gastroenterology organization global guideline: Helicobacter Pylori in developing countries. J dig dis 2011;12:319-26.

30. Garg B, Sandhu V, Sood N, et al. Histopathological analysis of chronic gastritis and correlation of pathological features with each other and endoscopic finding. Polish J pathol 2012;3:172-8.

31. Collins JSA, Sloan JM, Hamilton PW, et al. Investigation of the relationship between gastric antral inflammation and Campylobacter Pylori using graphic table planimetry. J Pathol 1989;159:281-5.

32. Jiro Watari, Nancy Chen, Kiron M. Das. Helicobacter Pylori associated chronic gastritis, clinical syndromes, precancerous lesions, and pathogenesis of gastric cancer development. World J Gastroenterol 2014; 20(18):546-54

33. Morson BC, Dawsan IMP, Spriggs Al, et al. Gastrointestinal pathology $2^{\text {nd }}$ ed. 1979. Blackwell Sicentific publications. p.91,95-97,101,103-105.

34. Caselli M. H.pylori, intestinal metaplasia, and gastric cancer: Histopathological point of view. Am J Gastrenterol 1996; 91(7): 1473- 4.

35. Olaejirinde Olaniyi, Olaofeetal. Are view of clinicopathologic characteristic of intestinal metaplasia in gastric mucosal biopsies. Pan Afr Med J 2016;23:77-82.

36. Hassawi BA. Prevalence of intestinal metaplasia and dysplasia in infectious and non infectious chronic gastritis. Int J Res Med Sci 2015;3(9): 2222-31.

37. Sternberg SS, Antonioli DA, Carter D, et al. Diagnositc surgical pathology. $3^{\text {rd }}$. Ed. 1999. Lipincott Williams and Wilkins.p. 540,541,542,544,546,550.

38. Ibrahim BH, Anim JT and Sarkar C. H. pylori associated chronic antral gastritis in Kuwait-a histopathological study. Ann Med 1995; 15(9):570-4.

39. Craanen ME, Dekker W, Blok P, et al. Intestinal metaplasia and $\mathrm{H}$. pylori: an endoscopic biopsy study of the gastric antrum. Gut 1992;33: 16-20.

40. Mansoor I. Prevalence of H. Pylori in Saudi Arabia. Qatar Med J 2001;10(2):43-6.

41. Mohamed AE, Al- Karawi MA, Al- Jumah AA, et al. $H$. pylori: prevalence in 532 consecutive patients with dyspepsia. J Ann Saudi Med 1994;14:134-5. 